\title{
Trapezoidal Intuitionistic Fuzzy Multiattribute Decision Making Method Based on Cumulative Prospect Theory and Dempster-Shafer Theory
}

\author{
Xihua Li, Fuqiang Wang, and Xiaohong Chen \\ School of Business, Central South University, Changsha 410083, China \\ Correspondence should be addressed to Fuqiang Wang; 1533194080@qq.com
}

Received 25 May 2014; Revised 27 July 2014; Accepted 28 July 2014; Published 24 August 2014

Academic Editor: Reinaldo Martinez Palhares

Copyright (C) 2014 Xihua Li et al. This is an open access article distributed under the Creative Commons Attribution License, which permits unrestricted use, distribution, and reproduction in any medium, provided the original work is properly cited.

\begin{abstract}
With respect to decision making problems under uncertainty, a trapezoidal intuitionistic fuzzy multiattribute decision making method based on cumulative prospect theory and Dempster-Shafer theory is developed. The proposed method reflects behavioral characteristics of decision makers, information fuzziness under uncertainty, and uncertain attribute weight information. Firstly, distance measurement and comparison rule of trapezoidal intuitionistic fuzzy numbers are used to derive value function under trapezoidal intuitionistic fuzzy environment. Secondly, the value function and decision weight function are used to calculate prospect values of attributes for each alternative. Then considering uncertain attribute weight information, Dempster-Shafer theory is used to aggregate prospect values for each alternative, and overall prospect values are obtained and thus the alternatives are sorted consequently. Finally, an illustrative example shows the feasibility of the proposed method.
\end{abstract}

\section{Introduction}

Existing multiattribute decision making methods based on expected utility theory assume that decision makers are completely rational. However, under risk and uncertainty, due to the vagueness of the decision making problems and limited human cognition, the actual decision making behavior is not entirely rational but bounded rationality [1]. There are much evidence, such as Allais paradox [2], the certainty effect [3], showing that, under risk and uncertainty, the expected utility theory is not valid as a descriptive theory for individual's decision making as it ignores the behaviors and cognitive factors of decision makers. On the basis of surveys and experiments, Kahneman and Tversky [3] proposed prospect theory which was further developed into cumulative prospect theory [4]. The prospect theory finds decision making behavior patterns which are not aware by expected utility theory. Since prospect theory can better reflect subjective risk attitude/preferences of the decision maker, it is more realistic to establish a prospect theory-based decision making method than an expected utility theory-based decision making method.

Recently, some scholars have incorporated prospect theory into multiattribute decision making. Bleichrodt et al. [5] studied the multiattribute utility under prospect theory, but there was no direct link between utilities and choices, and they did not provide data correlation process for the prescriptive analysis. In order to solve this problem, Gomes and Lima [6] proposed a method called TODIM which was a discrete MADM method used to solve riskless decision problems based on prospect theory, but its inability to deal with uncertainty and imprecision decision information affected its application. Then some scholars have considered the uncertainty and imprecision decision information, Wang and Sun [7] proposed a fuzzy multiple criteria decision making method based on prospect theory; Lahdelma and Salminen [8] introduced the SMAA-P method that combined the piecewise linear difference functions of prospect theory with SMAA; Liu et al. [9] researched the multiattribute 
decision making under risk with interval probability based on prospect theory and the uncertain linguistic variables; Krohling and de Souza [10] proposed a novel method based on prospect theory and fuzzy numbers. Peng et al. [11] proposed a random multiattribute decision making method based on prospect theory and trapezoidal fuzzy numbers.

However, the previous researches are inadequate. Due to the complexity of socioeconomic environment, in many practical decision making problems, the preferences over alternatives expressed by decision makers are usually imprecise; that is, there may be hesitation about preferences. In such case, intuitionistic fuzzy set, as an extension of Zadeh's fuzzy set [12], introduced by Atanassov [13], can be suitable and convenient to express the decision makers' preferences. Recently, intuitionistic fuzzy set received more and more attention [14-18]. However, both the fuzzy set and the intuitionistic fuzzy set only use discrete domains. Fuzzy numbers are special cases of fuzzy sets and are of importance for fuzzy multiattribute decision making problems [19-22]. Nehi and Maleki [23] introduced the trapezoidal intuitionistic fuzzy numbers as the extension of triangular intuitionistic fuzzy numbers. The trapezoidal intuitionistic fuzzy numbers are the extension of intuitionistic fuzzy sets in another way, which extends discrete set to continuous set, and they are the extension of fuzzy numbers [24]. Indeed some authors have noticed the advantage of trapezoidal intuitionistic fuzzy numbers in multiattribute decision making [25-28].

Furthermore, multiattribute decision making problems generally require decision makers to give attribute weight information. However, due to the complexity of the decision making environment, time pressure, lack of data, and limited information processing capability, attribute weight information has some uncertainty characteristics. Dempster-Shafer (D-S) theory [29] is an uncertain reasoning theory. It provides a unified framework for representing uncertain information allowing for representing "uncertainty," "ignorance," and other important concepts of cognitive science [30,31]. So we can use D-S theory to deal with uncertain attribute weight information in multicriteria decision making.

Motivated by the advantages of prospect theory, trapezoidal intuitionistic fuzzy numbers and D-S theory in multicriteria decision making, this paper proposes a novel multicriteria decision making method by combining cumulative prospect theory, trapezoidal intuitionistic fuzzy numbers, and D-S theory into multicriteria decision making. The proposed model has the following characteristics: behaviors and cognitive factors of decision making under risk are captured; imprecise and fuzzy information is depicted; uncertain attribute weight information is considered, which can provide decision makers with a complete picture of the decision problem in the uncertain environment.

This paper is organized as follows. In Section 2, we introduce some basic definitions of the trapezoidal intuitionistic fuzzy numbers, cumulative prospect theory, and D-S theory and define the gains and losses under trapezoidal intuitionistic fuzzy environment. In Section 3, a trapezoidal intuitionistic fuzzy multiattribute decision making method based on cumulative prospect theory and D-S theory is proposed. In Section 4, an illustrative example shows the feasibility and availability of the proposed method. Section 5 presents the comparison analysis with other corresponding works. Finally, some concluding remarks are drawn in Section 6.

\section{Preliminaries}

In this section, some basic definitions of trapezoidal intuitionistic fuzzy numbers, cumulative prospect theory, and D$S$ theory are introduced.

\subsection{Trapezoidal Intuitionistic Fuzzy Numbers}

Definition 1 (see [13]). Let $X$ be a universe of discourse. Then an intuitionistic fuzzy set $A$ in $X$ is given by

$$
A=\left\{\left\langle X, \mu_{A}(x), v_{A}(x) \mid x \in X\right\rangle\right\},
$$

where $\mu_{A}(x): X \rightarrow[0,1], \nu_{A}(x): X \rightarrow[0,1]$ with the condition

$$
0 \leq \mu_{A}(x)+\nu_{A}(x) \leq 1, \quad \forall x \in X .
$$

The numbers $\mu_{A}(x)$ and $v_{A}(x)$ denote the degree of membership and nonmembership of the element $x$ to the set $A$, respectively. In addition, the degree of hesitancy of $x$ can be computed as follows:

$$
\pi_{A}(x)=1-\mu_{A}(x)-v_{A}(x), \quad \forall x \in X .
$$

Obviously, if $\pi_{A}(x)=0$, then the intuitionistic fuzzy set reduces to a fuzzy set.

A trapezoidal intuitionistic fuzzy number is a special intuitionistic fuzzy set.

Definition 2 (see [24]). Let $A$ be a trapezoidal intuitionistic fuzzy number on a real number set $R$, and its membership is defined as follows:

$$
\mu_{A}(x)= \begin{cases}\frac{x-a}{b-a} \mu_{A}, & a \leq x<b ; \\ \mu_{A}, & b \leq x \leq c ; \\ \frac{d-x}{d-c} \mu_{A}, & c<x \leq d ; \\ 0, & \text { otherwise }\end{cases}
$$

Its nonmembership is defined as follows:

$$
v_{A}(x)= \begin{cases}\frac{b-x+v_{A}\left(x-a_{1}\right)}{b_{2}-b_{1}}, & a_{1} \leq x<b ; \\ \frac{v_{A},}{x-c+v_{A}\left(d_{1}-x\right)} & b \leq x \leq c ; \\ d_{1}-c & c<x \leq d_{1} \\ 0, & \text { otherwise }\end{cases}
$$

where $0 \leq \mu_{A} \leq 1,0 \leq v_{A} \leq 1, \mu_{A}+v_{A} \leq 1 ; a, b, c, d, a_{1}, d_{1} \in$ $R, A=\left\langle\left([a, b, c, d] ; \mu_{A}\right),\left(\left[a_{1}, b, c, d_{1}\right] ; v_{A}\right)\right\rangle$ is called a trapezoidal intuitionistic fuzzy number. Generally, in trapezoidal intuitionistic fuzzy number $A$, there are $a=a_{1}, d=d_{1}$. Then trapezoidal intuitionistic fuzzy number $A$ is denoted by $A=\left([a, b, c, d] ; \mu_{A}, v_{A}\right)$. 
We call $\pi_{A}=1-\mu_{A}-\nu_{A}$ the degree of hesitancy of the trapezoidal intuitionistic fuzzy number $A$. Obviously, if $b=c$ in the trapezoidal intuitionistic fuzzy number $A, A$ reduces to a triangular intuitionistic fuzzy number.

Definition 3. Let $A=\left(\left[a_{1}, b_{1}, c_{1}, d_{1}\right] ; \mu_{A}, v_{A}\right), B=\left(\left[a_{2}, b_{2}\right.\right.$, $\left.\left.c_{2}, d_{2}\right] ; \mu_{B}, v_{B}\right)$ be two trapezoidal intuitionistic fuzzy numbers on a real number set $R$; then the Hamming distance between them is defined as follows:

$$
\begin{aligned}
d(A, B)=\frac{1}{8} & \left(\left|\left(1+\mu_{A}-v_{A}\right) a_{1}-\left(1+\mu_{B}-v_{B}\right) a_{2}\right|\right. \\
& +\left|\left(1+\mu_{A}-v_{A}\right) b_{1}-\left(1+\mu_{B}-v_{B}\right) b_{2}\right| \\
& +\left|\left(1+\mu_{A}-v_{A}\right) c_{1}-\left(1+\mu_{B}-v_{B}\right) c_{2}\right| \\
& \left.+\left|\left(1+\mu_{A}-v_{A}\right) d_{1}-\left(1+\mu_{B}-v_{B}\right) d_{2}\right|\right) .
\end{aligned}
$$

For a trapezoidal intuitionistic fuzzy number $A=$ $\left([a, b, c, d] ; \mu_{A}, v_{A}\right)$, Wang and Zhang [24] defined the expected value $E$, score function $S$, and accuracy function $H$ of trapezoidal intuitionistic fuzzy number as follows:

$$
\begin{gathered}
E(A)=\frac{1}{8} \times\left[(a+b+c+d) \times\left(1+\mu_{A}-v_{A}\right)\right] ; \\
S(A)=E(A) \times\left(\mu_{A}-v_{A}\right) ; \\
H(A)=E(A) \times\left(\mu_{A}+v_{A}\right) .
\end{gathered}
$$

According to the expected value $E$, score function $S$, and accuracy function $H$, the comparison rule between two trapezoidal intuitionistic fuzzy numbers $A=\left(\left[a_{1}, b_{1}, c_{1}, d_{1}\right]\right.$; $\left.\mu_{A}, v_{A}\right)$ and $B=\left(\left[a_{2}, b_{2}, c_{2}, d_{2}\right] ; \mu_{B}, v_{B}\right)$ can be defined as follows:

$$
\begin{aligned}
& \text { if } S(A)>S(B) \text {, then } A>B \text {; } \\
& \text { if } S(A)=S(B) \text {, then consider the following: } \\
& \text { (1) if } H(A)>H(B) \text {, then } A>B \text {; } \\
& \text { (2) if } H(A)=H(B) \text {, then } A=B .
\end{aligned}
$$

2.2. Cumulative Prospect Theory. The prospect, denoted by $f=\left(x_{1}, p_{1} ; x_{2}, p_{2} ; \ldots ; x_{n}, p_{n}\right)$, is the basic research unit in prospect theory which yields outcome $x_{i}$ with probability $p_{i}$ [3]. Cumulative prospect theory, a development of prospect theory, has emerged as one of the most prominent alternatives to the expected utility theory [32].

Value function together with decision weight function determines the prospect value in cumulative prospect theory.

Cumulative prospect theory defines the value associated with gains or losses from a reference point rather than the absolute amount of wealth. Tversky and Kahneman [4] proposed a value function that can well meet the reversing of risk aversion/risk seeking in case of gains or losses, which is defined as follows:

$$
v\left(\Delta x_{i}\right)= \begin{cases}\left(\Delta x_{i}\right)^{\alpha} & \Delta x \geq 0 \\ -\lambda\left(-\Delta x_{i}\right)^{\beta} & \Delta x \leq 0,\end{cases}
$$

where $\Delta x_{i}$ is the difference between outcome $x_{i}$ and the reference point $x_{0}$; there is a gain if $x_{i}$ is larger than $x_{0}$ and a loss if $x_{i}$ is smaller than $x_{0}$; the coefficients $\alpha$ and $\beta$ indicate the curvature of the value function for gains and losses, respectively; the coefficient $\lambda$ indicates that the loss area is steeper than gains region in value function.

If the outcome $x_{i}$ and reference point $x_{0}$ are expressed with trapezoidal intuitionistic fuzzy numbers, then $\Delta x_{i}$ can be calculated by the following formula:

$$
\Delta x_{i}= \begin{cases}d\left(x_{i}, x_{0}\right) & x_{i} \geq x_{0} \\ -d\left(x_{i}, x_{0}\right) & x_{i}<x_{0} .\end{cases}
$$

In cumulative prospect theory, prospect value of a prospect $f$ is determined by both value function $v$ and decision weight function $\pi$. Prospect value of the prospect $f$ can be calculated by the following formulas:

$$
\begin{aligned}
& V(f)=V\left(f^{+}\right)+V\left(f^{-}\right), \\
& V\left(f^{+}\right)=\sum_{i=k+1}^{n} \pi_{(i)}{ }^{+} v\left(\Delta x_{(i)}\right), \\
& V\left(f^{-}\right)=\sum_{i=1}^{k} \pi_{(i)}{ }^{-} v\left(\Delta x_{(i)}\right),
\end{aligned}
$$

where (i) indicates a permutation on $\{1,2, \ldots, n\}$ such that $\Delta x_{(1)} \leq \Delta x_{(2)} \leq \cdots \leq \Delta x_{(k)} \leq 0 \leq \Delta x_{(k+1)} \leq \cdots \leq \Delta x_{(n)}$; decision weight function $\pi$ can be calculated by capacity function $w$ :

$$
\begin{gathered}
\pi_{(1)}{ }^{-}=w^{-}\left(p_{(1)}\right), \\
\pi_{(n)}{ }^{+}=w^{+}\left(p_{(n)}\right), \\
\pi_{(i)}{ }^{+}=w^{+}\left(p_{(i)}+\cdots+p_{(n)}\right)-w^{+}\left(p_{(i+1)}+\cdots+p_{(n)}\right), \\
k<i \leq n-1, \\
\pi_{(i)}{ }^{-}=w^{-}\left(p_{(1)}+\cdots+p_{(i)}\right)-w^{-}\left(p_{(1)}+\cdots+p_{(i-1)}\right), \\
2 \leq i \leq k .
\end{gathered}
$$

For prospects under risk, Prelec [33] gave $w^{+}$and $w^{-}$as follows:

$$
\begin{aligned}
w^{+}\left(\sum_{j=i}^{n} p_{(j)}\right) & =\exp \left(-\gamma^{+}\left(-\ln \left(\sum_{j=i}^{n} p_{(j)}\right)\right)^{\varphi}\right), \\
w^{-}\left(\sum_{j=1}^{i} p_{(j)}\right) & =\exp \left(-\gamma^{-}\left(-\ln \left(\sum_{j=i}^{n} p_{(j)}\right)\right)^{\varphi}\right),
\end{aligned}
$$

where $\gamma^{+}, \gamma^{-}$, and $\varphi$ are model parameters.

2.3. D-S Theory. In the decision making methods based on evidence theory, the decision makers preferences are expressed by mass function. Mass function can well describe the concept of "incomplete information," "inaccurate information," and "information uncertain." Mass function is built 
on the basis of the recognition framework. Assuming there is a judgment issue, with $\Theta$ representing all the possible answers to the question and all elements in the complete collection $\Theta$ being independent, then we call the complete set $\Theta$ a recognition framework. Then, according to Shafer [29], we introduce another important concept in the D-S theory: basic probability distribution function.

Definition 4. Let $\Theta$ be recognition framework. If the set function $m: 2^{\Theta} \rightarrow[0,1]$ satisfies

$$
\begin{gathered}
m(\emptyset)=0, \\
\sum_{A \subseteq \Theta} m(A)=1,
\end{gathered}
$$

then we call $m(A)$ basic probability distribution function on recognition framework $\Theta$.

$m(A)$ represents decision maker's exact trust degree for proposition $A$. For the empty set, the exact trust degree for proposition $A$ is 0 . If the decision maker fully trusts on proposition $A$, then $m(A)=1$. If the exact trust degree is greater than 0 , we call the element a focal element.

If we use D-S theory in the decision making process, the evidence should be integrated. In literature, there are many operators for information aggregation. The ordered weighted averaging (OWA) operator [34] is a very common operator which provides a wide range of the parametric aggregation operators including the maximum, minimum, and arithmetic average. In view of the advantages of D$S$ theoretical framework and OWA operator in uncertain information processing, Yager [35] developed a more general aggregation operator.

Definition 5. Ordered weighted average operator based on D$S$ theory, denoted by DS-OWA, can be defined as

$$
\text { DS - OWA }\left(a_{1}, a_{2}, \ldots, a_{n}\right)=\sum_{k=1}^{r} \sum_{j_{k}=1}^{q_{k}} m\left(B_{k}\right) w_{j_{k}} b_{j_{k}}
$$

where $w_{j_{k}}$ is the weight vector associated with the $k$ th focal element, satisfying $w_{j_{k}} \in[0,1], \sum_{j_{k}=1}^{q_{k}} w_{j_{k}}=1 ; b_{j_{k}}$ is the $j_{k}$ th largest number of the $a_{i_{k}} ; a_{i}$ is parameter variable, $m\left(B_{k}\right)$ is a basic probability assignment, $q_{k}$ is the cardinal number of the $k$ th focal element, and $r$ is the sum of focal elements.

\section{Multiattribute Decision Making Method Based on Cumulative Prospect Theory}

For a multiattribute decision making problem under risk and uncertainty, let $A=\left\{A_{1}, A_{2}, \ldots, A_{m}\right\}$ be a set of alternatives and $C=\left\{c_{1}, c_{2}, \ldots, c_{n}\right\} n$ decision attributes; for each attribute $c_{j}$, there are $l_{j}$ possible natural states $\left\{s_{1}, s_{2}, \ldots, s_{l_{j}}\right\}$ with probability $p_{j t}$, and the preference value of attribute $c_{j}$ on alternative $A_{i}$ is $\tilde{x}_{i j t}$ which is expressed in the form of trapezoidal intuitionistic fuzzy numbers. Different attributes have different reference points. For attribute $c_{j}$, reference point is denoted by $\widetilde{r}_{j 0}$.
With these notations, we introduce our novel trapezoidal intuitionistic fuzzy multiattribute decision making method based on cumulative prospect theory and D-S theory as follows.

Step 1. Obtain decision matrix $D=\left(\tilde{x}_{i j}\right)_{m \times n}$, where $\tilde{x}_{i j}=$ $\left(\tilde{x}_{i j 1}, p_{j 1} ; \tilde{x}_{i j 2}, p_{j 2} ; \ldots ; \tilde{x}_{i l_{j}}, p_{j l_{j}}\right)$ is the trapezoidal intuitionistic fuzzy prospect of attribute $c_{j}$ on alternative $A_{i}$. To eliminate the impact of different dimensions of decision information, decision matrix should be normalized. If $\widetilde{x}_{i j t}=$ $\left(\left[a_{i j t}^{1}, a_{i j t}^{2}, a_{i j t}^{3}, a_{i j t}^{4}\right] ; \mu_{i j t}, v_{i j t}\right)$, then in the normalized decision $\operatorname{matrix} D^{\prime}=\left(\widetilde{x}_{i j}^{\prime}\right)_{m \times n}, \tilde{x}_{i j}^{\prime}=\left(\widetilde{x}_{i j 1}^{\prime}, p_{j 1} ; \widetilde{x}_{i j 2}^{\prime}, p_{j 2} ; \ldots ; \tilde{x}_{i l_{j}}^{\prime}, p_{j l_{j}}\right)$ where $\tilde{x}_{i j t}^{\prime}=\left(\left[b_{i j t}^{1}, b_{i j t}^{2}, b_{i j t}^{3}, b_{i j t}^{4}\right] ; \mu_{i j t}, v_{i j t}\right)$, for the cost attributes

$$
b_{i j t}^{q}=\frac{\max _{i, t}\left(a_{i j t}^{4}\right)-a_{i j t}^{5-q}}{\max _{i, t}\left(a_{i j t}^{4}\right)-\min _{i, t}\left(a_{i j t}^{1}\right)}, \quad q=1,2,3,4 ;
$$

for the benefit attributes

$$
b_{i j t}^{q}=\frac{a_{i j t}^{q}-\min _{i, t}\left(a_{i j t}^{1}\right)}{\max _{i, t}\left(a_{i j t}^{4}\right)-\min _{i, t}\left(a_{i j t}^{1}\right)}, \quad q=1,2,3,4 .
$$

Step 2. Selection of reference point $\widetilde{r}_{j 0}$ : for attribute $c_{j}$, the decision maker determines the reference point according to his/her risk appetite and mental state. Generally, the status quo, the goals, and aspirations or the minimum requirement can be selected as a reference point [36]. Similarly, the reference point $\widetilde{r}_{j 0}$ should be converted into a normalized value $\tilde{r}_{j 0}^{\prime}$ according to formula (17) or (18) to eliminate the impact of different dimensions of decision information.

Step 3. For each trapezoidal intuitionistic fuzzy prospect $\tilde{x}_{i j}^{\prime}$, calculate its value function by the following formula:

$$
z_{i j t}=v\left(\Delta \tilde{x}_{i j t}^{\prime}\right)
$$

where $v(x)$ is the value function in formula (8) and $\Delta \tilde{x}_{i j t}^{\prime}$ is the difference between outcome $\tilde{x}_{i j t}^{\prime}$ and the reference point $\tilde{r}_{j 0}^{\prime}$ :

$$
\Delta \tilde{x}_{i j t}^{\prime}= \begin{cases}d\left(\tilde{x}_{i j t}^{\prime}, \widetilde{r}_{j 0}\right) & \tilde{x}_{i j t}^{\prime} \geq \widetilde{r}_{j 0}^{\prime} \\ -d\left(\tilde{x}_{i j t}^{\prime}, \widetilde{r}_{j 0}\right) & \tilde{x}_{i j t}^{\prime}<\widetilde{r}_{j 0}^{\prime}\end{cases}
$$

Step 4. For each trapezoidal intuitionistic fuzzy prospect $\tilde{x}_{i j}^{\prime}$, calculate its prospect value by formulas (10) (14); then the normalized decision matrix $D^{\prime}=\left(\tilde{x}_{i j}^{\prime}\right)_{m \times n}$ is converted into prospect value matrix $P=\left(z_{i j}\right)_{m \times n}$.

Step 5. The determination of attribute weight information by mass function: firstly, compose $\Theta=\left\{c_{1}, c_{2}, \ldots, c_{n}\right\}$ as a frame of discernment. Then decision makers give attribute weight information according to their experience, knowledge, and observations. It is worth mentioning that, due to the complexity of the decision making environment, time pressure, lack of data, limited information processing capability, and 
decision makers may usually consider one or more attributes at the same point which compose collections of elements and assign a number to each evidence representing the support degree of the collection [29]. Assuming that decision makers give mass function for $k$ collections of elements after the value judgments, $\left\{B_{1}, B_{2}, \ldots, B_{l}\right\}$ are focal elements in evidence belief structure, probabilities assigned to each focal element are $m\left(B_{k}\right)$, and the number of elements in each focal element is $q_{k}$.

Step 6. For different focal element $B_{k}$, determine the weighting vector $w$ for OWA operator. Decision makers may use different weight determination methods according to their interests.

Step 7. For each alternative $A_{i}$, aggregate the prospect value $z_{i j}$ into an overall prospect value $z_{i}$ by using DS-OWA operator in Definition 5.

Step 8. Rank the alternatives according to the size of overall prospects. The alternative with the biggest $z_{i}$ can be considered as the best alternative.

\section{Illustrative Example}

Now suppose that a venture capital company wants to select the most appropriate alternative to investment. After preevaluation, three alternatives $A_{1}, A_{2}$, and $A_{3}$ have remained as alternatives for further selection. The four possible alternatives can be evaluated under four criteria: (1) growth $c_{1}$, (2) economic benefits $c_{2}$, (3) social benefits $c_{3}$, and (4) environmental impact $c_{4}$. For attributes $c_{1}$ and $c_{2}$, there are four possible natural states $\left\{s_{1}, s_{2}, s_{3}, s_{4}\right\}$, representing "very good," "good," "general," and "bad," respectively. For attributes $c_{3}$ and $c_{4}$, there are three possible states $\left\{s_{1}, s_{2}, s_{3}\right\}$ representing "very good," "good," and "general."

According to the proposed novel trapezoidal intuitionistic fuzzy multiattribute decision making method, the procedure for alternative selection mainly contains the following steps.

(1) In order to evaluate three alternatives, based on his own experience and statistics, the decision maker firstly gives the reference value $\tilde{x}_{i j}$ of attribute $c_{j}$ on alternative $A_{i}$, as shown in Tables 1, 2, 3, and 4 . Suppose the probability of each natural state can be forecasted as $p_{j t}$; then according to the reference value $\tilde{x}_{i j}$ and probability $p_{j t}$, we can obtain the trapezoidal intuitionistic fuzzy prospect $\widetilde{x}_{i j}=\left(\widetilde{x}_{i j 1}, p_{j 1} ; \widetilde{x}_{i j 2}\right.$, $\left.p_{j 2} ; \ldots ; \tilde{x}_{i l_{j}}, p_{j l_{j}}\right)$; thus, the decision matrix $D=$ $\left(\widetilde{x}_{i j}\right)_{m \times n}$ can be obtained. To eliminate the impact of the different dimensions of decision information, formulas (18), for attributes $c_{1}, c_{2}$, and $c_{3}$, and (17) for attribute $c_{4}$ are used to convert the decision matrix $D=\left(\tilde{x}_{i j}\right)_{m \times n}$ into the normalized decision matrix $D^{\prime}=\left(\tilde{x}_{i j}^{\prime}\right)_{m \times n}$.

(2) In order to obtain prospect value of attribute $c_{j}$ on each alternative, the decision maker determines the reference point $\widetilde{r}_{j 0}$ according to his/her risk appetite and mental state. Suppose the given reference points are as follows: $\widetilde{r}_{10}=([2,3,4,6] ; 0.6,0.2) ; \widetilde{r}_{20}=([2,3$, $5,6] ; 0.7,0.2) ; \widetilde{r}_{30}=([2,3,4,5] ; 0.6,0.2) ; \tilde{r}_{40}=([2,3$, $4,6] ; 0.7,0.1)$. Similarly, the reference point $\widetilde{r}_{j 0}$ is converted to normalized value $\widetilde{r}_{j 0}^{\prime}$ according to formula (17) or (18).

(3) For each trapezoidal intuitionistic fuzzy prospect $\widetilde{x}_{i j}^{\prime}$, calculate its value function $z_{i j t}$ by formulas (8), (19), and (20), where in formula (8), in view of Tversky and Kahneman [4], the coefficients $\alpha=\beta=$ $0.88, \lambda=2.25$. And then, according to formulas (10) (14), calculate prospect value $z_{i j}$ of prospect $\widetilde{x}_{i j}^{\prime}$, where in formula (14), in view of Goda and Hong [37], the coefficients $\gamma^{+}=\gamma^{-}=0.8, \varphi=1.0$. Thus the normalized decision matrix $D^{\prime}=\left(\tilde{x}_{i j}^{\prime}\right)_{m \times n}$ is converted to prospect value matrix $P=\left(z_{i j}\right)_{m \times n}$ as shown in Table 5.

(4) In order to determine evidence belief structure, decision makers discuss the importance of each attribute and finally give the belief structure on discernment frame $\Theta=\left\{c_{1}, c_{2}, \ldots, c_{n}\right\}$ according to their experience, knowledge, and observations as follows:

$$
\begin{aligned}
& m\left\{B_{1}\right\}=m\left\{c_{1}, c_{3}\right\}=0.5 ; \\
& m\left\{B_{2}\right\}=m\left\{c_{2}, c_{3}\right\}=0.2 ; \\
& m\left\{B_{3}\right\}=m\left\{c_{1}, c_{4}\right\}=0.3 .
\end{aligned}
$$

(5) Here we use the normal distribution method [38] to determine the weighting vector $w$ for OWA operator with two arguments:

$$
w_{2}=(0.7,0.3) \text {. }
$$

(6) For each alternative $A_{i}$, aggregate the prospect value $z_{i j}$ into an overall prospect value $z_{i}$ by using DS-OWA operator in Definition 5, and we get

$$
z_{1}=0.0199, \quad z_{2}=0.0278, \quad z_{3}=0.0640 .
$$

Rank the alternatives according to the size of overall prospect values:

$$
A_{3}>A_{2}>A_{1} .
$$

The alternative $A_{3}$ has the biggest $z_{i}$, so the best alternative is $A_{3}$.

\section{Comparison Analysis with Other Corresponding Works}

Compared with other corresponding works, the advantages of our proposed method in this paper are summarized as follows.

(1) The existing multiattribute decision making methods based on expected utility theory ignore the decision maker's risk psychological factors, while our proposed 
TABLE 1: Prospect information for attribute $c_{1}$.

\begin{tabular}{lcccc}
\hline & $s_{1}$ & $s_{2}$ & $s_{3}$ & $s_{4}$ \\
\hline & 0.1 & 0.3 & 0.4 & 0.2 \\
$A_{1}$ & $([3,5,6,8] ; 0.8,0.1)$ & $([2,3,4,5] ; 0.7,0.2)$ & $([2,3,4,5] ; 0.8,0.1)$ & $([2,3,4,5] ; 0.6,0.2)$ \\
$A_{2}$ & $([4,5,6,7] ; 0.7,0.2)$ & $([2,3,4,5] ; 0.5,0.3)$ & $([1,2,4,6] ; 0.7,0.2)$ & $([1,2,3,5] ; 0.5,0.1)$ \\
$A_{3}$ & $([1,2,3,4] ; 0.6,0.2)$ & $([3,4,5,6] ; 0.6,0.2)$ & $([2,3,4,5] ; 0.7,0.1)$ & $([2,3,5,6] ; 0.6,0.2)$ \\
\hline
\end{tabular}

TABLE 2: Prospect information for attribute $c_{2}$.

\begin{tabular}{lcccc}
\hline & $s_{1}$ & $s_{2}$ & $s_{3}$ & $s_{4}$ \\
\hline & 0.2 & 0.3 & 0.2 & 0.3 \\
$A_{1}$ & $([4,5,6,8] ; 0.5,0.1)$ & $([3,4,5,6] ; 0.6,0.3)$ & $([3,4,5,6] ; 0.8,0.1)$ & $([1,2,3,4] ; 0.6,0.3)$ \\
$A_{2}$ & $([3,4,6,7] ; 0.7,0.1)$ & $([3,4,5,6] ; 0.7,0.2)$ & $([1,2,3,4] ; 0.6,0.1)$ & $([2,3,4,5] ; 0.6,0.3)$ \\
$A_{3}$ & $([4,5,6,7] ; 0.6,0.1)$ & $([2,3,5,7] ; 0.7,0.2)$ & $([1,2,3,4] ; 0.7,0.2)$ & $([2,3,4,5] ; 0.7,0.1)$ \\
\hline
\end{tabular}

TABle 3: Prospect information for attribute $c_{3}$.

\begin{tabular}{ccc}
\hline$s_{1}$ & $s_{2}$ & $s_{3}$ \\
\hline 0.3 & 0.3 & 0.4 \\
$A_{1}([2,3,4,6] ; 0.7,0.1)$ & $([2,4,5,6] ; 0.6,0.3)$ & $([2,3,4,5] ; 0.5,0.4)$ \\
$A_{2}([3,4,5,6] ; 0.6,0.2)$ & $([4,5,6,7] ; 0.5,0.2)$ & $([1,2,4,5] ; 0.6,0.2)$ \\
$A_{3}([2,3,4,5] ; 0.6,0.1)$ & $([2,3,4,5] ; 0.8,0.1)$ & $([1,2,3,4] ; 0.7,0.2)$ \\
\hline
\end{tabular}

TABLE 4: Prospect information for attribute $c_{4}$.

\begin{tabular}{ccc}
\hline$s_{1}$ & $s_{2}$ & $s_{3}$ \\
\hline 0.2 & 0.5 & 0.3 \\
$A_{1}([3,4,5,6] ; 0.5,0.1)$ & $([1,2,3,4] ; 0.7,0.1)$ & $([3,4,5,7] ; 0.7,0.2)$ \\
$A_{2}([2,4,5,6] ; 0.7,0.2)$ & $([2,3,4,5] ; 0.6,0.1)$ & $([1,2,3,5] ; 0.4,0.3)$ \\
$A_{3}([4,5,6,7] ; 0.5,0.4)$ & $([3,4,5,6] ; 0.4,0.3)$ & $([2,3,4,5] ; 0.8,0.1)$ \\
\hline
\end{tabular}

TABle 5: Prospect value matrix $P=\left(z_{i j}\right)_{m \times n}$.

\begin{tabular}{lcccc}
\hline & $c_{1}$ & $c_{2}$ & $c_{3}$ & $c_{4}$ \\
\hline$A_{1}$ & 0.060 & -0.171 & -0.111 & -0.123 \\
$A_{2}$ & -0.063 & -0.134 & 0.045 & -0.212 \\
$A_{3}$ & 0.006 & -0.038 & -0.105 & -0.444 \\
\hline
\end{tabular}

method based on cumulative prospect theory in this paper can reflect well the subjective risk attitude/preferences of the decision maker. The proposed method fully takes into account the bounded rationality of the decision maker in decision making under uncertainty.

(2) The existing multiattribute decision making methods based on prospect theory in literature [6-11] only use crisp values, fuzzy numbers, and linguistic variables to express decision information while our proposed method in this paper uses trapezoidal intuitionistic fuzzy numbers to depict uncertain and fuzzy information. Compared with crisp values, fuzzy numbers, and linguistic variables, trapezoidal intuitionistic fuzzy numbers in this paper can accurately describe the imprecise and vague preferences in decision making under uncertainty.
(3) Compared with multiattribute decision making methods based on trapezoidal intuitionistic fuzzy numbers in the literature [25-28], our proposed method in this paper noticed the uncertainty existing in the knowledge of attributes and used D-S theory to deal with the uncertain attribute weight information in multicriteria decision making.

(4) Compared with other corresponding works, this paper combines prospect theory, trapezoidal intuitionistic fuzzy numbers, and D-S theory to multicriteria decision making and provides decision makers with a complete view of the decision problem in the uncertain environment.

\section{Conclusions}

The prospect theory finds decision making behavior patterns constituting violations of the expected utility theory. Since the prospect theory can better reflect subjective risk preferences of the decision makers, the prospect theory-based decision making method is of more practical value than expected utility theory-based method. For risky decision making problems where attribute values are in the form of trapezoidal intuitionistic fuzzy numbers and where attribute weights are uncertain, this paper proposes a trapezoidal intuitionistic fuzzy multiattribute decision making method based on cumulative prospect theory and D-S theory and gives the specific steps of the proposed method. On the one hand, the proposed method reflects the psychological and behavioral characteristics of decision makers; on the other hand, the proposed method reflects the information fuzziness under uncertainty and the uncertain attribute weight information which is more in line with realistic decisions making. The proposed method provides a guideline for the multiattribute decision making under risk and uncertainty.

\section{Conflict of Interests}

The authors declare that there is no conflict of interests regarding the publication of this paper. 


\section{Acknowledgments}

This research work was supported by the National Natural Sciences Foundation of China (nos. 71221061, 71401184), China Postdoctoral Science Foundation (no. 2014M552169), and Central South University Business Management Postdoctoral Research Station.

\section{References}

[1] H. A. Simon, "A behavioral model of rational choice," Quarterly Journal of Economics, vol. 69, no. 1, pp. 99-118, 1955.

[2] M. Allais, "Le comportement de l'homme rationnel devant le risque," Econometrica. Journal of the Econometric Society, vol. 21, pp. 503-546, 1953.

[3] D. Kahneman and A. Tversky, "Prospect theory: an analysis of decision under risk," Econometrica, vol. 47, no. 2, pp. 263-292, 1979.

[4] A. Tversky and D. Kahneman, "Advances in prospect theory: cumulative representation of uncertainty," Journal of Risk and Uncertainty, vol. 5, no. 4, pp. 297-323, 1992.

[5] H. Bleichrodt, U. Schmidt, and H. Zank, "Additive utility in prospect theory," Management Science, vol. 55, no. 5, pp. 863873, 2009.

[6] L. F. A. M. Gomes and M. M. P. P. Lima, "TODIM: basics and application to multicriteria ranking of projects with environmental impacts," Foundations of Computing and Decision Sciences, vol. 16, no. 4, pp. 113-127, 1992.

[7] J. Wang and T. Sun, "Fuzzy multiple criteria decision making method based on prospect theory," in Proceeding of the International Conference on Information Management, Innovation Management and Industrial Engineering (ICIII '08), vol. 1, pp. 288-291, Taipei, Taiwan, December 2008.

[8] R. Lahdelma and P. Salminen, "Prospect theory and stochastic multicriteria acceptability analysis (SMAA)," Omega, vol. 37, no. 5, pp. 961-971, 2009.

[9] P. Liu, F. Jin, X. Zhang, Y. Su, and M. Wang, "Research on the multi-attribute decision-making under risk with interval probability based on prospect theory and the uncertain linguistic variables," Knowledge-Based Systems, vol. 24, no. 4, pp. 554-561, 2011.

[10] R. A. Krohling and T. T. M. de Souza, "Combining prospect theory and fuzzy numbers to multi-criteria decision making," Expert Systems with Applications, vol. 39, no. 13, pp. 11487-11493, 2012.

[11] L. Y. Peng, P. Liu, Z. Liu, and Y. Su, "Research on the random multi-attribute decision-making methods with trapezoidal fuzzy probability based on prospect theory," Journal of Intelligent \& Fuzzy Systems, vol. 26, pp. 2131-2141, 2014.

[12] L. A. Zadeh, "Fuzzy sets," Information and Computation, vol. 8, pp. 338-353, 1965.

[13] K. T. Atanassov, "Intuitionistic fuzzy sets," Fuzzy Sets and Systems, vol. 20, no. 1, pp. 87-96, 1986.

[14] G. Beliakov, M. Pagola, and T. Wilkin, "Vector valued similarity measures for Atanassov's intuitionistic fuzzy sets," Information Sciences, vol. 280, pp. 352-367, 2014.

[15] Y. D. He, H. Chen, L. Zhou, J. Liu, and Z. Tao, "Intuitionistic fuzzy geometric interaction averaging operators and their application to multi-criteria decision making," Information Sciences, vol. 259, pp. 142-159, 2014.
[16] Y. D. He, H. Chen, L. G. Zhou, B. Han, Q. Y. Zhao, and J. P. Liu, "Generalized intuitionistic fuzzy geometric interaction operators and their application to decision making," Expert Systems with Applications, vol. 41, no. 5, pp. 2484-2495, 2014.

[17] S. P. Wan and D. F. Li, "Atanassov's intuitionistic fuzzy programming method for heterogeneous multiattribute group decision making with Atanassov's intuitionistic fuzzy truth degrees," IEEE Transaction of Fuzzy Systems, vol. 22, pp. 300-312, 2014.

[18] L. Y. Zhang, T. Li, and X. H. Xu, "Consensus model for multiple criteria group decision making under intuitionistic fuzzy environment," Knowledge-Based Systems, vol. 57, pp. 127135, 2014.

[19] D. Dubois and H. Prade, Fuzzy Sets and Systems: Theory and Applications, Academic Press, New York, NY, USA, 1980.

[20] S. Abbasbandy and T. Hajjari, "A new approach for ranking of trapezoidal fuzzy numbers," Computers and Mathematics with Applications, vol. 57, no. 3, pp. 413-419, 2009.

[21] B. Asady and A. Zendehnam, "Ranking fuzzy numbers by distance minimization," Applied Mathematical Modelling, vol. 31, no. 11, pp. 2589-2598, 2007.

[22] A. Hadi-Vencheh and M. Allame, "On the relation between a fuzzy number and its centroid," Computers and Mathematics with Applications, vol. 59, no. 11, pp. 3578-3582, 2010.

[23] H. M. Nehi and H. R. Maleki, "Intuitionistic fuzzy numbers and its applications in fuzzy optimization problem," in Proceedings of the 9th WSEAS International Conference on Systems, pp. 1-5, Athens, Greece, 2005.

[24] J. Q. Wang and Z. Zhang, "Aggregation operators on intuitionistic trapezoidal fuzzy number and its application to multi-criteria decision making problems," Journal of Systems Engineering and Electronics, vol. 20, no. 2, pp. 321-326, 2009.

[25] J. Ye, "Expected value method for intuitionistic trapezoidal fuzzy multicriteria decision-making problems," Expert Systems with Applications, vol. 38, no. 9, pp. 11730-11734, 2011.

[26] S. Wan, "Power average operators of trapezoidal intuitionistic fuzzy numbers and application to multi-attribute group decision making," Applied Mathematical Modelling: Simulation and Computation for Engineering and Environmental Systems, vol. 37, no. 6, pp. 4112-4126, 2013.

[27] J. Wu and Q. W. Cao, "Same families of geometric aggregation operators with intuitionistic trapezoidal fuzzy numbers," Applied Mathematical Modelling, vol. 37, no. 1-2, pp. 318-327, 2013.

[28] X. H. Li and X. H. Chen, "Extension of the TOPSIS method based on prospect theory and trapezoidal intuitionistic fuzzy numbers for group decision making," Journal of Systems Science and Systems Engineering, vol. 23, no. 2, pp. 231-247, 2014.

[29] G. Shafer, A Mathematical Theory of Evidence, Princeton University Press, Princeton, NJ, USA, 1976.

[30] G. Wei, X. Zhao, and R. Lin, "Some hybrid aggregating operators in linguistic decision making with Dempster-Shafer belief structure," Computers and Industrial Engineering, vol. 65, no. 4, pp. 646-651, 2013.

[31] W. Yang and Y. F. Pang, "The quasi-arithmetic triangular fuzzy OWA operator based on Dempster-Shafer theory," Journal of Intelligent \& Fuzzy Systems, vol. 26, pp. 1123-1135, 2014.

[32] U. Schmidt and H. Zank, "Risk aversion in cumulative prospect theory," Management Science, vol. 54, no. 1, pp. 208-216, 2008.

[33] D. Prelec, “The probability weighting function," Econometrica, vol. 66 , no. 3, pp. 497-527, 1998. 
[34] R. R. Yager, "On ordered weighted averaging aggregation operators in multicriteria decisionmaking," IEEE Transactions on Systems, Man, and Cybernetics, vol. 18, no. 1, pp. 183-190, 1988.

[35] R. R. Yager, "Decision making under Dempster-Shafer uncertainties," Studies in Fuzziness and Soft Computing, vol. 219, pp. 619-632, 2008.

[36] G. J. Koop and J. G. Johnson, "The use of multiple reference points in risky decision making," Journal of Behavioral Decision Making, vol. 25, no. 1, pp. 49-62, 2012.

[37] K. Goda and H. P. Hong, "Application of cumulative prospect theory: implied seismic design preference," Structural Safety, vol. 30, no. 6, pp. 506-516, 2008.

[38] Z. S. Xu, "An overview of methods for determining OWA weights," International Journal of Intelligent Systems, vol. 20, no. 8, pp. 843-865, 2005. 


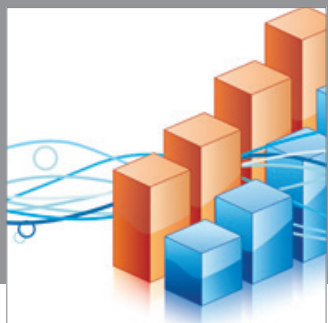

Advances in

Operations Research

mansans

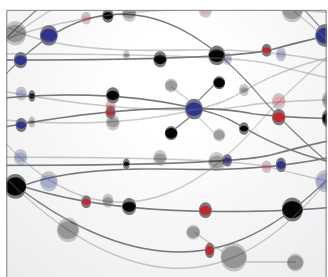

The Scientific World Journal
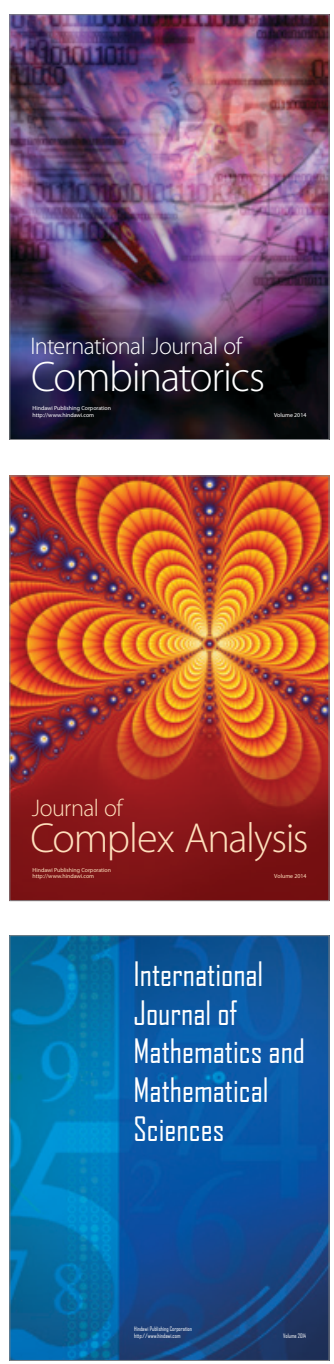
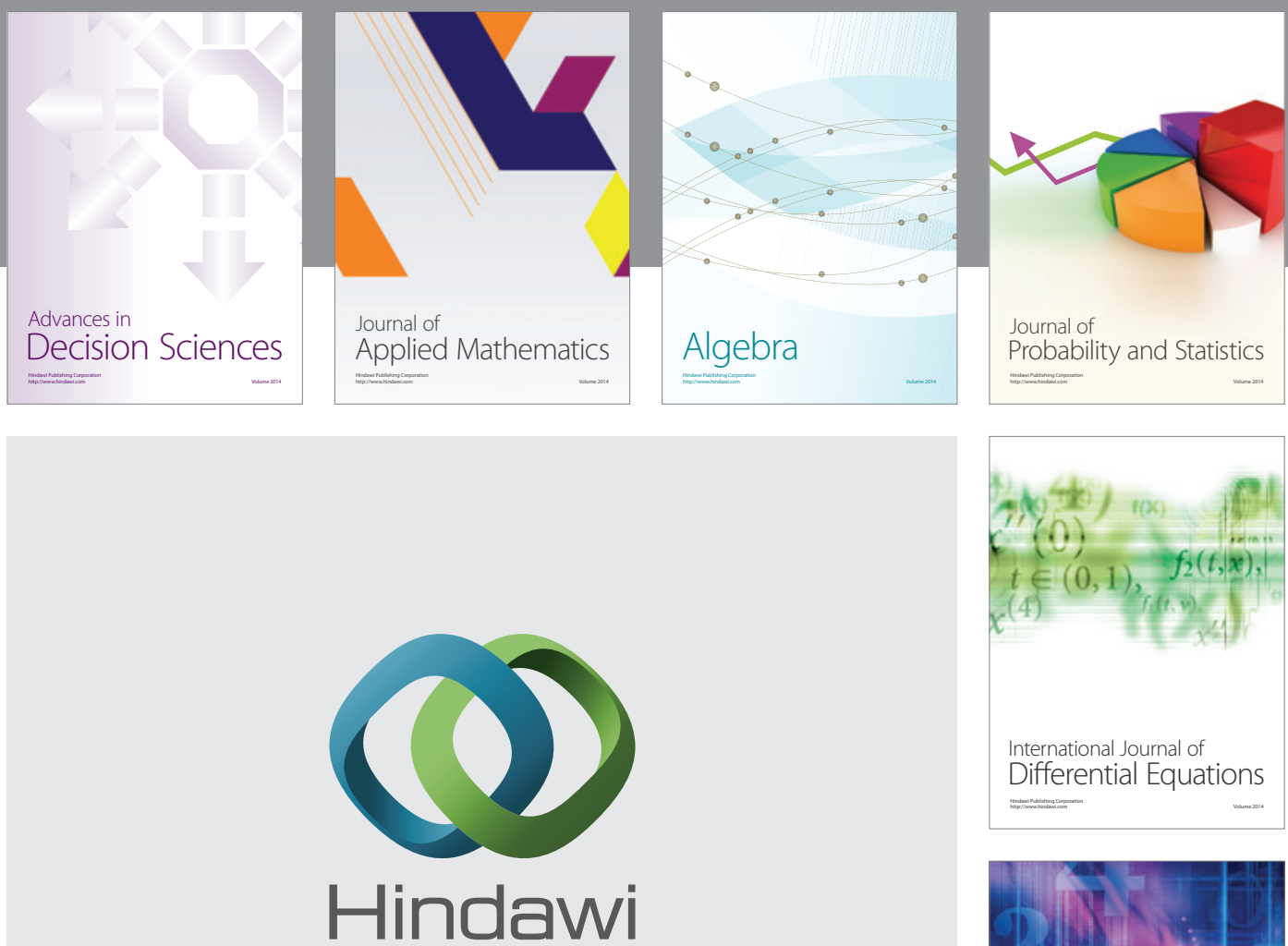

Submit your manuscripts at http://www.hindawi.com
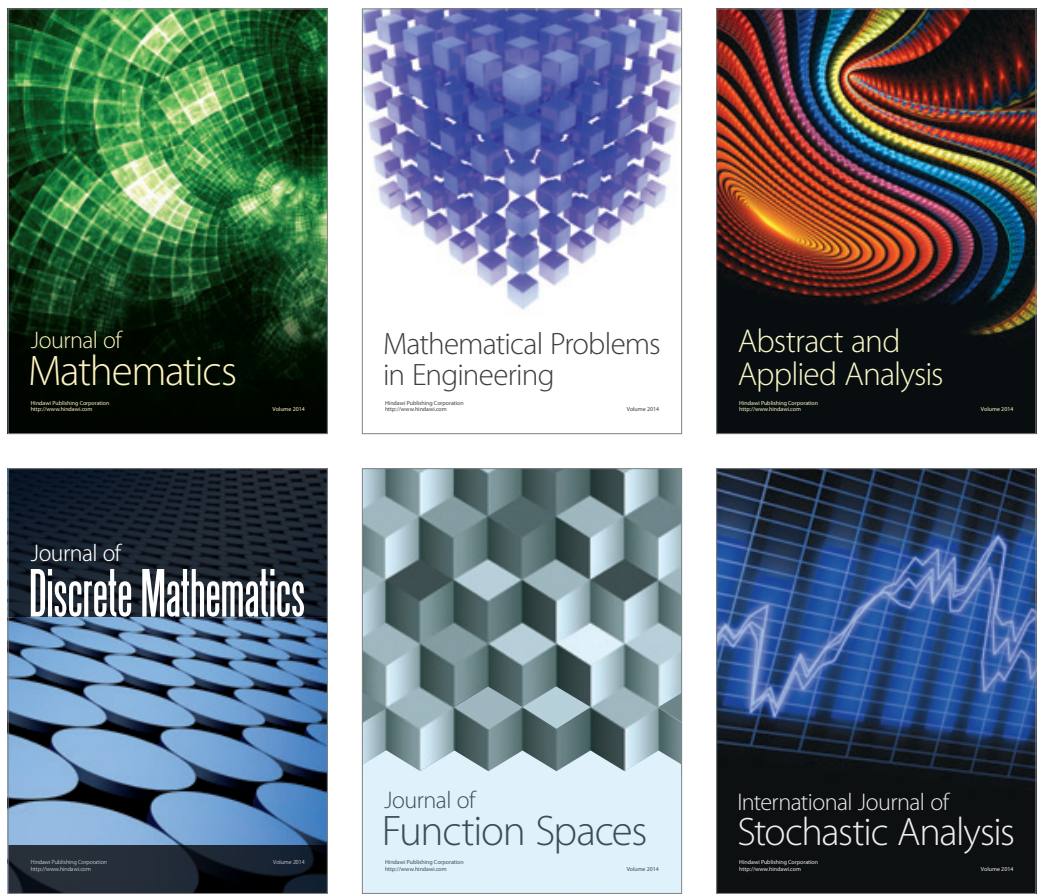

Journal of

Function Spaces

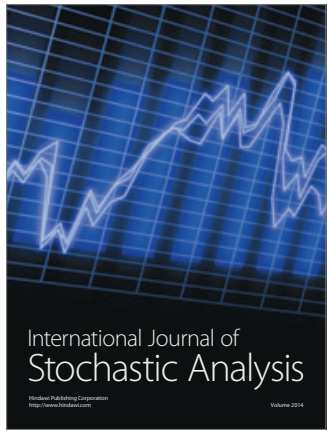

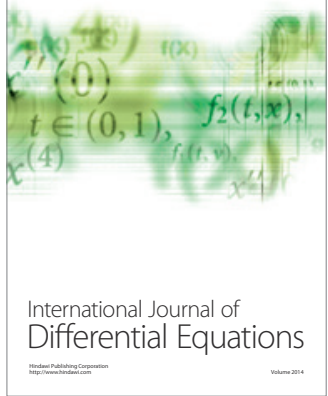
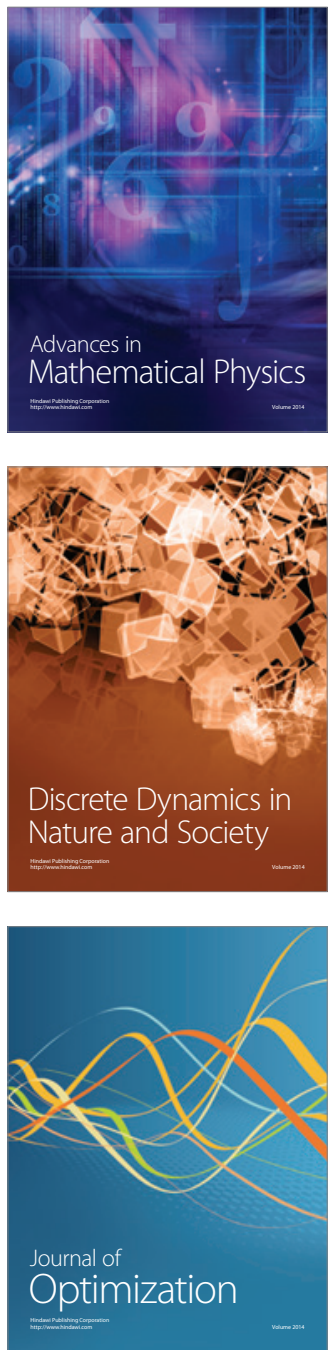